\title{
Authors' Reply to the Letter by Shoar et al. on "Glycosylated Hemoglobin as a Surrogate for the Prevention of Cardiovascular Events in Cardiovascular Outcome Trials Comparing New Antidiabetic Drugs to Placebo"
}

\author{
Pierre Ambrosi ${ }^{a, b}$ Aurélie Daumas ${ }^{a}$ Patrick Villani ${ }^{a}$ Roch Giorgi ${ }^{c}$ \\ ${ }^{a}$ Department of Therapeutics, Hôpital de la Timone, Marseille, France; b ${ }^{b}$ Department of Cardiology, \\ Hôpital de la Timone, Marseille, France; ' $A$ Aix Marseille Univ, APHM, INSERM, IRD, SESSTIM, Sciences \\ Economiques et Sociales de la Santé et Traitement de I'Information Médicale, Hop Timone, BioSTIC, \\ Biostatistique et Technologies de I'Information et de la Communication, Marseille, France
}

\section{Dear Editor,}

According to the suggestion by Shoar et al. [1], we tested the robustness of the correlation between $\mathrm{HbA1c}$ reduction and MACE decrease, performing sensitivity analyses [2].

The predictive value of $\mathrm{HbA} 1 \mathrm{c}$ for coronary events has been consistently shown in the early period following an acute coronary event [3]. There is also some evidence that $\mathrm{HbA1c}$ predicts survival in diabetic patients with stable coronary artery disease [4]. In our meta-analysis, 2 trials included patients with a recent acute coronary syndrome and 12 trials included patients either at high risk or with definite coronary artery disease (stable or unstable). Excluding the 2 trials performed after an acute coronary syndrome did not modify the correlation $(R=$ $0.88, p=0.0004$ ).

In the 5 trials testing a DPP-4 inhibitor, the relative MACE reduction was at most 3\%, despite a significant (modest) reduction in $\mathrm{HbAlc}$. Excluding these 5 trials did not modify the correlation between $\mathrm{HbAlc}$ reduction and MACE decrease $(R=0.84, p=0.004)$.

Lastly, we excluded the SUSTAIN-6 trial showing the higher MACE decrease (26\%). The correlation was not significantly modified $(R=0.88, p<0.001)$.

Thus, we are confident that $\mathrm{HbA1c}$ reduction explains, at least in part, the decrease in MACE observed with the new antidiabetic drugs.

\section{References}

karger@karger.com

www.karger.com/crd

(c) 2020 S. Karger AG, Basel

Karger ${ }^{\prime \prime}=$
1 Shoar S, Naderan M, Shoar N, Modukuru VR. Letter to the Editor concerning "Glycosylated Hemoglobin as a Surrogate for the Prediction of Cardiovascular Events in Cardiovascular Outcome Trials Comparing New Antidiabetic Drugs to Placebo". Cardiology. 2020.

2 Ambrosi P, Daumas A, Villani P, Giorgi R. Glycosylated Hemoglobin as a Surrogate for the Prevention of Cardiovascular Events in Cardiovascular Outcome Trials Comparing New Antidiabetic Drugs to Placebo. Cardiology. $2020 \mathrm{Feb} ; 1-5$.
3 Pan W, Lu H, Lian B, Liao P, Guo L, Zhang M Prognostic value of $\mathrm{HbAlc}$ for in-hospital and short-term mortality in patients with acute coronary syndrome: a systematic review and meta-analysis. Cardiovasc Diabetol. 2019 Dec;18(1):169.

4 Mancini GB, Maron DJ, Hartigan PM, Spertus JA, Kostuk WJ, Berman DS, et al.; COURAGE Trial Research Group. Lifestyle, glycosylated hemoglobin Alc, and survival among patients with stable ischemic heart disease and diabetes. J Am Coll Cardiol. 2019 Apr;73(16):2049-58.
Pierre Ambrosi

Department of Cardiology

Hôpital de la Timone

Rue Saint-Pierre, FR-13385 Marseille (France)

pierre.ambrosi@ap-hm.fr 